\title{
Reducing Postoperative Pain from Tonsillectomy Using Monopolar Electrocautery by Cooling the Oropharynx
}

\author{
Lucas Vieira $^{1} \quad$ Leonardo Nissen $^{1} \quad$ Gustavo Sela ${ }^{1}$ Yara Amara ${ }^{1} \quad$ Vinicius Fonseca ${ }^{1}$ \\ ${ }^{1}$ Department of Otorrinolaringologia, Hospital da Cruz Vermelha, \\ Curitiba, Paraná, Brazil \\ Int Arch Otorhinolaryngol 2014;18:155-158. \\ Address for correspondence Lucas Vieira, Physician, Department of \\ Otorrinolaringologia, Hospital da Cruz Vermelha, Rua Vicente \\ Machado 1310, Curitiba, PR, 80420-011, Brazil \\ (e-mail: lucasvieira89@gmail.com).
}

\begin{abstract}
Objective Evaluate intraoperative cooling of the oropharynx to reduce postoperative pain in tonsillectomy using monopolar electrocautery.

Methods Sixty-six patients, age 1 to 12 years, were selected for the study, 33 in the control group and 33 in the experimental group. After randomization, patients underwent subcapsular dissection and hemostasis with monopolar electrocautery. Patients in the experimental group had the oropharynx cooled after tonsil dissection and hemostasis for 10 minutes. The procedure was done through the oral cavity by irrigation with $500 \mathrm{~mL}$ of $0.9 \%$ saline, in temperatures between $5^{\circ} \mathrm{C}$ and $10^{\circ} \mathrm{C}$, for 5 minutes. The evaluation of postoperative pain was made with the pain visual analog scale (VAS) for 10 days. As complementary data on the evaluation of pain, we recorded daily use of ketoprofen for pain relief.

\section{Keywords}

- postoperative pain

- tonsillectomy

- cautery

Results Pain after tonsillectomy assessed by VAS was significantly lower in the experimental group at days 0,5 , and $6(p<0.05)$. There were no differences in the use of ketoprofen between the groups.

Conclusion Cooling of the oropharynx after tonsillectomy promotes clinically significant reduction in postoperative pain, without additional complications.
\end{abstract}

\section{Introduction}

The first description of a surgical technique for tonsillectomy was performed by Aulus Cornelius Celsus, a Roman physician of the time of Christ, who extracted the tonsils using just his fingers. ${ }^{1}$ Currently, tonsillectomy is one of the most common surgical procedures in the world and the most common in otolaryngology. ${ }^{1,2}$ Over the past decade, there has been progress in surgical and anesthetic techniques for tonsillectomy, resulting in faster surgeries with fewer complications. ${ }^{3}$ Despite the evolution to what is currently considered a safe procedure, pain and bleeding after tonsillectomy remain important surgical complications. ${ }^{2-4}$

Post-tonsillectomy pain is attributed to a combination of nervous irritation, inflammation, and spasm of the pharyn- geal muscles. Several strategies have been studied to achieve better safety and efficacy in relieving postoperative pain, including pharmacologic alternatives, surgical techniques, and cooling of the operative area. ${ }^{3}$

\section{Objective}

Evaluate the use of cooling the oropharynx intraoperatively to reduce postoperative pain in tonsillectomy with the use of monopolar electrocautery in children.

\section{Literature Review}

Operative tonsillectomy pain is basically characterized by local tissue injury, which releases histamine and inflammatory received

September 16, 2013

accepted

October 27, 2013
DOI http://dx.doi.org/

10.1055/s-0033-1363783. ISSN $1809-9777$.
Copyright $\odot 2014$ by Thieme Publicações License terms Ltda, Rio de Janeiro, Brazil 
mediators that activate receptors of pain, causing the transduction and transmission of pain information to the central nervous system (CNS) and the process of neurogenic inflammation and vasodilatation determining extravasation of plasma in the periphery. ${ }^{5}$

New surgical techniques for tonsillectomy recently have been introduced as options: the harmonic scalpel and the coblation (plasma) and microdebrider. These devices operate at a much lower temperature $\left(60^{\circ} \mathrm{C}\right.$ to $\left.100^{\circ} \mathrm{C}\right)$ than electrocautery and thus are expected to cause less thermal damage and less postoperative pain. ${ }^{2}$

In contrast with these new techniques, dissection with electrocautery, commonly used as a method of choice, results in faster surgeries and promotes better hemostasis. However, it generates more heat $\left(400^{\circ} \mathrm{C}\right.$ to $\left.6,000^{\circ} \mathrm{C}\right)$ and thus produces greater thermal damage in tissues and nerve endings of the tonsillar and peritonsillar areas, resulting in greater pain, despite the high hemostatic power. ${ }^{2,3}$

Bipolar instruments (forceps and scissors) cause less thermal damage and less postoperative pain compared with electrocautery, but reports have demonstrated a higher incidence of postoperative pain and bleeding with these instruments compared with tonsillectomy performed by cold dissection with the scalpel. ${ }^{2}$

Several techniques have been studied for the management of postoperative pain. Local infiltration of anesthetic in the peritonsillar tissue to reduce post-tonsillectomy pain has not shown conclusive results. Steroids, delivered via either systemic administration or peritonsillar infiltration, was not effective in reducing pain. ${ }^{3}$ Some other agents, such as fibrin glue and sucralfate, have been used for wound healing, but with inconclusive results concerning pain reduction. ${ }^{3}$

The nerves are extremely sensitive to temperature, a fact that has promoted the implementation of cryoanalgesia in pain control. ${ }^{3,6}$ Cryoanalgesia can be applied percutaneously or directly on nerve endings with substances at low temperatures, such as liquid nitrogen or saline solution at $0.9 \%$. When these endings are cooled to $-200^{\circ} \mathrm{C}$ or less, they may be functionally inactive for 7 to 10 days due to production of crystals that degenerate the axon and its myelin structure preserving intraneural collagen, allowing total regeneration in 4 to 5 weeks. In this temperature, the other tissues do not suffer any damage. Thus, it was postulated that cooling the oropharynx immediately after tonsillectomy can cause neuropraxia of the exposed nerves, reducing inflammation and pain. This relatively simple technique does not seem to be associated with complications. $^{3,7}$

Horii et $\mathrm{al}^{2}$ conducted a study with 189 patients under 16 years of age, aiming to compare the post-tonsillectomy pain with bipolar scissors after cooling the pharyngeal mucosa with traditional cold dissection. Indications for surgery were recurrent tonsillitis, sleep apnea, and hypopnea obstructive syndrome and IgA nephropathy. The mucosa was cooled by oropharynx irrigation with saline solution at a temperature of $4^{\circ} \mathrm{C}$ for 10 minutes after removal of the tonsils. As a result, they achieved significantly lower levels of blood loss and postoperative pain assessed by visual analog scale (VAS) of pain in the control group.

\section{Materials and Methods}

The study was conducted after approval by the Research Ethics Committee of the Red Cross Hospital (HCV)-Branch of Paraná, from June to November 2012.

The inclusion criteria for surgery were obstructive symptoms or recurrent tonsillitis. Subjects undergoing surgery for other reasons, as well as patients with mental or physical disorders who were unable to be submitted to the protocols of anesthesia and postoperative analgesia, were excluded from the study. Patients or caregivers were given verbal and written information for study participation and also signed the consent form.

Patients were randomized into a control group and a study group, and only one surgeon performed the surgeries in the study. All the patients in the study immediately after the procedure received a single dose of analgesics (dipyrone and ketorolac) and antiemetic medication (ondansetron and dexamethasone).

Subcapsular dissection with hemostasis by electrocautery monopolar surgical technique was chosen for all tonsillectomies performed in the study. The randomized patients in the experimental group had the oropharynx cooled after tonsil dissection and hemostasis for 10 minutes. The oral cavity was irrigated with $500 \mathrm{~mL}$ of $0.9 \%$ saline solution, with a temperature between $5^{\circ} \mathrm{C}$ and $10^{\circ} \mathrm{C}$, for 5 minutes and then aspirated through the oropharynx. In the control group, no intervention was made after tonsil dissection and hemostasis.

Immediately after the procedure, both groups received routine care. All patients received postoperative analgesia with paracetamol every 6 hours and ketoprofen in cases of severe pain as assessed by parents or by subjects crying. Patients were also instructed to follow a standard soft/liquid diet after tonsillectomy.

Postoperative pain was assessed with the VAS. Pain was assessed with a 10 -cm ruler ( - Fig. 1) ranging from no pain (0) to severe pain (10). The patients' parents began the register on the day of surgery and were instructed to repeat this procedure twice a day, once in the morning and again in the evening, at the same times, before the analgesics use. Pain was evaluated for a period of 10 days after surgery. The follow-up of patients was performed typically at 10 and 30 postoperatively days.

In addition to the pain scale, the absolute amount of ketoprofen used for the pain relief, ranging from zero to three capsules due to the dosage, was recorded as complementary data that could influence the evaluation of postoperative pain.

The data were evaluated between the groups by analysis of variance with $p<0.05$ denoting significance using Statistica, Med Soft Inc., Tulsa, USA.

\section{Results}

The sample consisted of 66 patients age 1 to 12 years, 42 boys and 24 girls. After randomization, 33 patients (age 1 to 10 years) were placed in the experimental group and 33 patients (age 1 to 12 years) in the control group. 


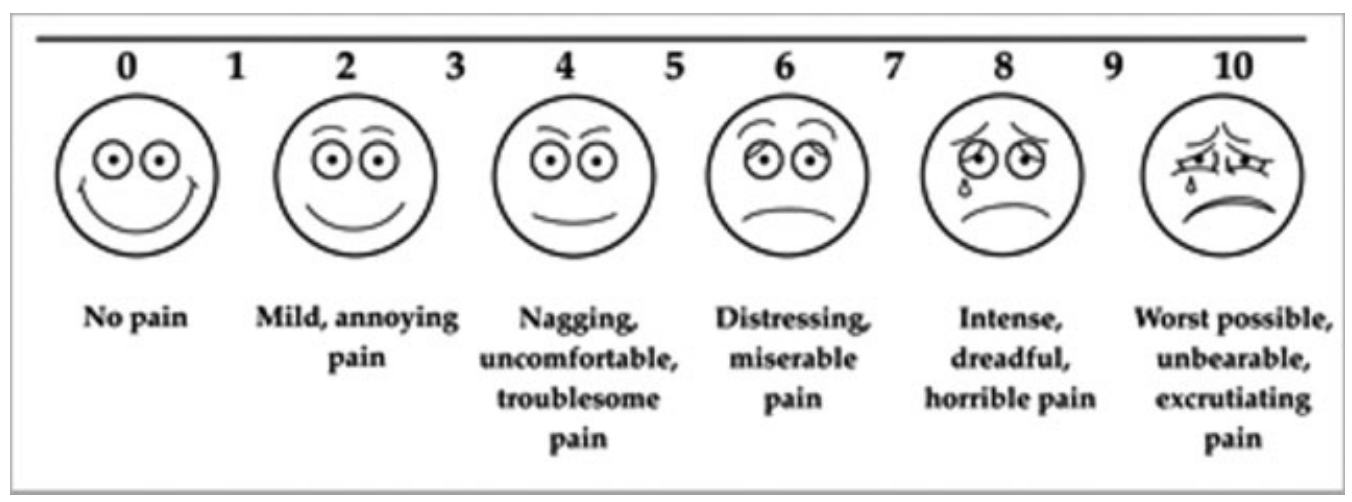

Fig. 1 Visual analog pain scale.

As shown in - Fig. 2, the post-tonsillectomy pain assessed by VAS was lower in the experimental group, in which the cooling technique was used (an average of 4.35 in the control group and 3.42 in the experimental group), with statistically significant differences on days 0,5 , and $6(p<0.05)$. The values obtained in the experimental group were lower than the control group on all days, except days 4 and 10, but it was not statistically significant.

In the pain assessment based on the need to use ketoprofen (-Table 1), there was no statistically significant difference between the groups during the study period. In the control group, the greatest day of ketoprofen use was day 7 $(2.76 \pm 0.33)$, and this day also had the highest average in pain scale $(6.3 \pm 0.33)$. In the experimental group, day 6 had the highest use of ketoprofen ( $2.89 \pm 0.39)$, but the biggest pain according to the VAS of pain, as well as in the control group, was on day 7 (5.33 \pm 0.33$)$.

\section{Discussion}

Numerous studies in the literature suggest that temperature is the most important factor in preventing tissue damage and postoperative pain. ${ }^{6}$ Horii et $\mathrm{al}^{2}$ first demonstrated that surgical techniques for tonsillectomy that use some kind of heat could reduce postoperative pain with some kind of cooling of the pharyngeal mucosa when compared with the cold technique.

The advantages of a local cold stimulus, according to Sylvester et al, ${ }^{6}$ include prevention of edema due to a decrease of the liquid inside the tissues, reduced inflammation, decreased metabolism, and better control of bleeding. In our

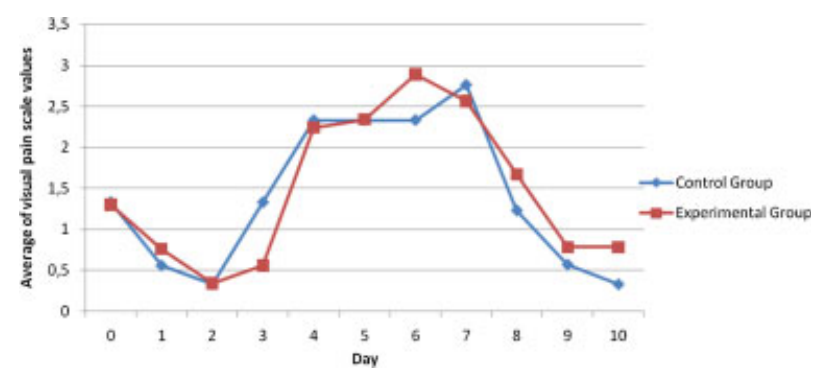

Fig. 2 Average visual pain scalevalues. study, we demonstrated that cooling the oropharynx results in clear and significant reduction of post-tonsillectomy pain during the 10-day follow-up after surgery.

The mean values of the pain scale, in both groups, gradually decreased during the first 3 days after surgery, then increased from the fourth day, with a peak of pain on the day 7 and further reduction from day 8 . This fact, as quoted by Cornejo et al, ${ }^{1}$ can be explained by the destruction of nerve endings in the tonsillar cavity promoted by the heat of electrocautery; these endings regenerate in the following days, increasing the perception of pain.

As an explanation for the similar ketoprofen consumption between groups, we hypothesized that the availability of medication and guidance to caregivers to administer the anti-inflammatory for possible cases of severe pain experienced by the patient, together with the existing emotional bond, could promote the administration of medication as a way to prevent pain, consciously or not, to prevent the patient's suffering.

Cryoanalgesia is a new technique for reducing post-tonsillectomy pain. Studies show that its use results in clear and significant reduction of post-tonsillectomy pain during the 10 days after surgery (28.3\% decrease in the evaluation of the visual scale of pain compared with the control group). These patients also returned to school or work 4 days earlier, on average, than those who received no intervention. It has been suggested that cryoanalgesia promotes a return to usual diet before the control group, as well as less need to use analgesics. ${ }^{3}$

In our study, cooling after tonsillectomy resulted in a $21.4 \%$ reduction in the average values obtained by VAS of pain. Few information is available in the literature about what degrees of reduction in scale values for pain are necessary to be considered clinically significant, with values ranging from 20 to $50 \%$, depending on the initial intensity of pain. We obtained a clinically important reduction in pain after tonsillectomy with cooling of the oropharynx.

Concerning the limitations of our study, we can mention the exclusive analysis of postoperative pain, not taking into consideration factors such as surgical time and blood loss, which could be factors that cause increased postoperative pain due to greater use of electrocautery. Another limiting factor to be considered is the subjectivity of pain assessment by caregivers, especially in younger children who have not 
Table 1 Assessing the need for ketoprofen

\begin{tabular}{|l|l|l|l|l|l|}
\hline \multirow{2}{*}{ Day } & \multicolumn{2}{|c|}{ Control group } & \multicolumn{2}{c|}{ Experimental group } & \multicolumn{1}{l|}{} \\
\cline { 2 - 6 } & Average & Standard deviation & Average & 1.3 & Standard deviation \\
\hline 0 & 1.33 & 0.23 & 0.76 & 0.33 & 0.033 \\
\hline 1 & 0.56 & 0.39 & 0.34 & 0.33 & 0.063 \\
\hline 2 & 0.33 & 0.33 & 0.56 & 0.25 & 0.078 \\
\hline 3 & 1.33 & 0.33 & 2.24 & 0.45 & 0.0786 \\
\hline 4 & 2.33 & 0.25 & 2.34 & 0.38 & 0.0763 \\
\hline 5 & 2.33 & 0.33 & 2.89 & 0.39 & 0.01 \\
\hline 6 & 2.33 & 0.39 & 2.56 & 0.33 & 0.009 \\
\hline 7 & 2.76 & 0.33 & 1.67 & 0.45 & 0.063 \\
\hline 8 & 1.23 & 0.25 & 0.78 & 0.25 & 0.067 \\
\hline 9 & 0.57 & 0.33 & 0.78 & 0.33 & \\
\hline 10 & 0.33 & 0.4 & & & 0.087 \\
\hline
\end{tabular}

developed adequate verbalization and cannot properly express the symptoms.

\section{Conclusion}

Our study demonstrated that the use of cooling in the oropharynx after tonsillectomy with the monopolar electrocautery can promote a clinically important reduction in postoperative pain, without additional complications, according to the assessment made by an objective and validated scale of pain.

\section{References}

1 Cornejo SS, Beltrán MC, Breinbauer KH, Fonseca AX, Serra TR. Dolor em amigdalectomía: Técnica fría versus electrobisturí mo- nopolar. Estudio prospectivo randomizado. Revista de otorrinolaringología y cirugía de cabeza y cuello 2010;70(2):123-128

2 Horii A, Hirose M, Mochizuki R, et al. Effects of cooling the pharyngeal mucosa after bipolar scissors tonsillectomy on postoperative pain. Acta Otolaryngol 2011;131(7):764-768

3 Robinson SR, Purdie GL. Reducing post-tonsillectomy pain with cryoanalgesia: a randomized controlled trial. Laryngoscope 2000; 110(7):1128-1131

4 Wiikmann V, Prado FAP, Caniello M, Di Francesco RC, Miziara ID. Complicações pós-operatórias em tonsilectomias. Braz J Otorhinolaryngol 2004;70(4):464-468

5 Vaz JLM, Vaz MC. Fisiopatologia da Dor Pós-Operatória. 1st ed. Rio de Janeiro, Brazil: Colégio Brasileiro de Cirurgiões; 2005

6 Sylvester DC, Rafferty A, Bew S, Knight LC. The use of ice-lollies for pain relief post-paediatric tonsillectomy. A single-blinded, randomised, controlled trial. Clin Otolaryngol 2011;36(6):566-570

7 Muñoz-Blanco F, Salmerón J. Complicaciones del dolor postoperatorio. Rev Soc Esp Dolor 2001;8(3):194-211 